\title{
Colonização por macroinvertebrados bentônicos em substrato artificial e natural em um riacho da serra de Itatinga, São Paulo, Brasil
}

\author{
Emerson Machado de Carvalho \& Virginia Sanches Uieda
}

Departamento de Zoologia, Instituto de Biociências, Universidade Estadual Paulista. Caixa Postal 510, 18618-000 Botucatu, São Paulo, Brasil. E-mail: ecarvalho@ibb.unesp.br; vsuieda@ibb.unesp.br

\begin{abstract}
Colonization by benthic macroinvertebrates in artificial and natural substrates in a mountain stream from Itatinga, São Paulo, Brazil. The artificial and natural substrates were compared regarding the colonization process by macroinvertebrates. At $1^{\text {st }} 3^{\text {rd }}, 7^{\text {th }}, 13^{\text {th }}, 21^{\text {st }}, 31^{\text {st }}$ and $42^{\text {nd }}$ sampling days the macroinvertebrate richness and abundance were analyzed. Chironomidae larva was the most abundant on both substrates during the whole sampling period (53\% on each substrate), followed by Oligochaeta (17 in artificial and $18 \%$ in natural), Ephemeroptera ( 16 and $11 \%$ ) and Trichoptera juveniles (10 and $11 \%$ ). The ecological succession process was similar on both substrates, with Oligochaeta as an important colonizer in earlier stages of the successional process. Other similarity between the substrates was the appearance of Ephemeroptera-Leptohyphidae at the $7^{\text {th }}$ sampling day, after what other groups started fluctuations on their abundance. In conclusion, the artificial substrate was appropriated for the macroinvertebrate colonization, showing similarity of the community structure and the process of ecological succession when compared to the natural one. For both substrates a stabilization period of the community composition happened between the $7^{\text {th }}$ and $13^{\text {th }}$ samplings days.

KEY WORDS. Community structure, manipulative experiments, tropical stream, ecological succession.
\end{abstract}

RESUMO. Substratos artificial e natural foram comparados quanto ao processo de colonização por macroinvertebrados. No $1^{\circ}, 3^{\circ}, 7^{\circ}, 13^{\circ}, 21^{\circ}, 31^{\circ}$ e $42^{\circ}$ dias de amostragem a riqueza e a abundância dos macroinvertebrados foi analisada. Larvas de Chironomidae foi o grupo mais abundante nos dois substratos durante todo o período amostral (53\% em cada substrato), seguido por Oligochaeta (17 no artificial e $18 \%$ no natural), formas imaturas de Ephemeroptera (16 e 11\%) e Trichoptera (10 e 11\%). O processo de sucessão ecológica foi similar nos dois substratos, sendo Oligochaeta um importante colonizador nos estágios iniciais do processo sucessional. Outra semelhança entre os substratos foi o aparecimento de Ephemeroptera-Leptohyphidae no sétimo dia de amostragem, após o que outros grupos apresentaram flutuações na sua abundância. Em conclusão, o substrato artificial foi apropriado para a colonização por macroinvertebrados, mostrando similaridade na estrutura da comunidade e nos processos de sucessão ecológica quando comparado ao substrato natural. Um período de estabilização na composição da comunidade ocorreu, para os dois substratos, entre e sétimo e $13^{\circ}$ dias de amostragem.

PALAVRAS CHAVE. Estrutura da comunidade, manipulação experimental, riacho tropical, sucessão ecológica.

Os macroinvertebrados compõem um grupo de grande importância ecológica em riachos, participando das cadeias alimentares e sendo o elo de ligação entre os recursos basais (detritos e algas) e os peixes. Sua grande diversidade e ocorrência em vários tipos de habitats também são fatores que os levam a ter um papel central no estudo da ecologia de riachos (Hynes 1970, Allan 1995).

Nos ambientes lóticos as comunidades de macroinvertebrados estão representadas por numerosos filos, incluindo Arthropoda, Mollusca, Annelida, Nematoda e Platyhelminthes. Muitas espécies estão associadas com a superfície do fundo do canal, sendo assim denominadas de fauna bentônica, ou cole- tivamente como macrozoobentos (HAUER \& RESH 1996).

A composição e a distribuição da fauna de macroinvertebrados de água doce são influenciadas por vários fatores ambientais, destacando-se a velocidade da corrente e o tipo de substrato (Hynes 1970, Resh \& Rosenberg 1984, Allan 1995). Além disso, segundo Allan (1995) os fatores ambientais interagem em sua ação sobre a biota, determinando uma grande diversidade e complexidade estrutural no ambiente.

Diversos experimentos relacionam a estabilidade física do substrato e a presença de detritos orgânicos com um aumento na riqueza e abundância de organismos (ver Allan 1995). Freitas (1998), em um estudo com diferentes tipos de substratos, 
atribuiu o início da colonização à estabilização do habitat e à presença de fungos e detritos originários da floresta.

Experimentos de colonização permitem conhecer a fauna de invertebrados presente numa área, como também possibilitam a análise das mudanças que ocorrem na composição da comunidade ao longo do tempo. Este processo de sucessão ecológica, definido por BROWER \& ZAR (1984) como uma reposição progressiva de uma comunidade por outra, envolve não somente uma mudança na composição de espécies, mas também alterações na biomassa e nas características do ambiente. A análise de um processo de sucessão primária, utilizando um substrato estéril, pode mostrar importantes aspectos da estrutura da comunidade ao longo do tempo (BROWER \& ZAR 1984). Inicialmente, táxons menos especializados invadem a área, modificando o ambiente de tal modo a permitir a invasão por outros grupos, que podem excluir seus predecessores.

No presente trabalho, o objetivo foi analisar a eficiência de colonização por macroinvertebrados bentônicos em substrato rochoso artificial quando comparado a um substrato natural, em um riacho de serra. Substratos artificiais têm a vantagem de permitir uma maior precisão dos dados, padronizando a área de amostragem e o tempo inicial do processo de colonização. A hipótese de trabalho é de que o substrato artificial confeccionado permitirá uma colonização semelhante à do substrato natural em função de oferecer condições físicas semelhantes para a colonização (rugosidade, perfurações imitando o espaço intersticial, área de superfície disponível). Pela análise da composição e abundância das espécies nos dois tipos de substrato, ao longo de um período de colonização, três questões foram investigadas: a) A composição da comunidade de macroinvertebrados é significativamente semelhante nos dois tipos de substrato? 2) Qual o tempo de colonização necessário para uma estabilização na riqueza e abundância das espécies? 3) Seria a seqüência de reposição de espécies envolvida no processo de sucessão ecológica analisado semelhante nos dois tipos de substrato?

\section{MATERIAL E MÉTODOS}

\section{Área de estudo}

O experimento foi realizado no Ribeirão da Quinta, Município de Itatinga, São Paulo, o qual nasce nas escarpas da borda leste da Cuesta de Botucatu, dirigindo-se para oeste, e desaguando no Ribeirão da Posse, afluente do Rio Santo Inácio. O trecho trabalhado localiza-se no Sítio Pedra Branca ( $\left.23^{\circ} 06^{\prime} 47^{\prime \prime} \mathrm{S}, 48^{\circ} 29^{\prime} 46^{\prime \prime} \mathrm{W}\right)$, a $743 \mathrm{~m}$ de altitude, no km $204 \mathrm{da}$ Rodovia Castelo Branco. O experimento foi instalado num "rápido" (run, conforme descrição de RINCón 1999), com 6 m de comprimento e $4 \mathrm{~m}$ de largura, sendo sombreado por mata de galeria. Este trecho pode ser caracterizado por apresentar pequena profundidade $(30-40 \mathrm{~cm})$, correnteza moderada $(0,15$ $\mathrm{m} / \mathrm{s}), \mathrm{pH}$ variando entre 7,4 e 7,9, temperatura da água entre 15 e $22^{\circ} \mathrm{C}$ e fundo arenoso-rochoso recoberto por uma fina camada de matéria orgânica particulada.

Revista Brasileira de Zoologia 21 (2): 287-293, junho 2004

\section{Desenho experimental}

O experimento foi conduzido nos meses de julho e agosto, correspondendo ao período seco na região de estudo. Para o experimento foram utilizados dois tipos de substrato rochoso (Fig. 1): artificial e natural. O substrato artificial foi confeccionado com cimento (40\%), areia fina (40\%) e pedras $(20 \%$ de cascalho do riacho), na forma de um retângulo $(8,0$ x 6,0 x $2,5 \mathrm{~cm}$ ), com área total de superfície de $210 \mathrm{~cm}^{2}$ (somada a área de seis furos distribuídos verticalmente). Para dar maior resistência, este substrato, depois de seco, foi queimado em forno caseiro $\left(200^{\circ} \mathrm{C}\right.$ por quatro horas). $\mathrm{O}$ substrato natural era formado por um conjunto de nove pedras, com aproximadamente 2,8 centímetros de diâmetro cada, previamente selecionadas no riacho, lavadas e ensacadas em tela de arame $(1 \mathrm{~cm}$ de malha), com área total de superfície semelhante à do substrato artificial. $\mathrm{O}$ arame servia para manter as pedras juntas e dispostas em uma única camada. O substrato artificial também foi ensacado em tela de arame para manter a mesma estrutura experimental. No dia 18 de julho de 2001, os substratos foram distribuídos aleatoriamente no leito do riacho, sendo retiradas duas réplicas de cada tipo de substrato ao $1^{\circ}, 3^{\circ}, 7^{\circ}, 13^{\circ}, 21^{\circ}$, $31^{\circ}$ e $42^{\circ}$ dias de colonização.

O substrato retirado foi acondicionado em frascos com álcool a 70\%, sendo adicionado o corante Rosa de Bengala (diluição de $12 \mathrm{mg} / \mathrm{l})$. Posteriormente, o substrato foi lavado e escovado em bandeja plástica, sendo o material resultante da lavagem despejado em peneiras granulométricas $(1,00 ; 0,50 \mathrm{e}$ $0,25 \mathrm{~mm})$. As peneiras foram vistoriadas sob estereomicroscópio, sendo os macroinvertebrados triados, identificados e mensurados quanto à abundância (número de indivíduos) e área ocupada $\left(\mathrm{mm}^{2}\right)$ por cada grupo taxonômico. O cálculo da área foi obtido através do mensuramento dos organismos sobre uma placa milimetrada, com o auxílio de um estereomicroscópio. Como o tamanho reduzido dos organismos dificultava a determinação da biomassa, o cálculo da área serviu como uma medida do tamanho relativo dos diversos táxons amostrados, a qual analisada em conjunto com a abundância permitiu verificar a importância relativa dos táxons na ocupação da área do substrato disponibilizada para colonização. A identificação dos macroinvertebrados foi realizada com auxílio de chaves de identificação (Pennak 1978, Lopretto \& Tell 1995, Merritt \& Cummins 1996), sendo a categoria de família o menor nível taxonômico utilizado para determinação das UTO's (Unidade Taxonômica Operacional). Para algumas ordens não foi possível identificar em nível de família os exemplares de ínstar inicial, devido à dificuldade de visualização das características utilizadas nas chaves.

\section{Análise dos dados}

Como pré-requisitos na escolha dos testes adequados para análise dos dados de abundância e área ocupada, foram aplicados testes de normalidade (Shapiro-Wilks; $\alpha=0,05$ ) e homocedasticidade (Levene; $\alpha=0,05$ ) (StATsoft 1996). 

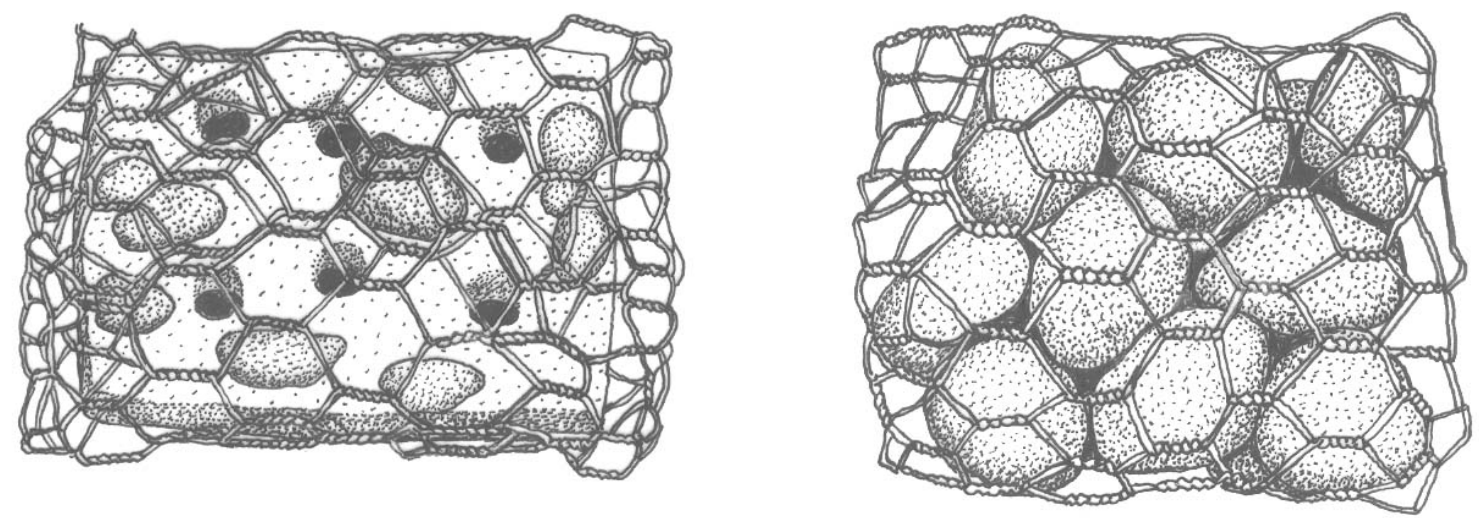

Figura 1. Substrato artificial (confeccionado com cimento e pedras) e substrato natural (composto por nove pedras), envoltos em tela de arame (malha $1 \mathrm{~cm}$ ), utilizados no experimento de colonização por macroinvertebrados.

Para avaliar se a abundância e a área ocupada pelos macroinvertebrados diferiram quando comparados os substratos artificial e natural, foi utilizada uma Análise de Variância (ANOVA, $\alpha=0,05)$ para medidas repetidas (Systat 1997). Esta técnica paramétrica avalia o efeito das variáveis independentes (tipo de substrato) na variação de uma variável dependente (abundância e área ocupada). A ANOVA para medidas repetidas foi utilizada no presente trabalho devido ao efeito do tempo de colonização, onde se considerou as sete amostragens (dias de colonização) como medidas repetidas.

O processo de sucessão ecológica foi estudado quantitativamente considerando as mudanças na abundância de macroinvertebrados ao longo do processo de colonização. Esta análise foi aplicada para as cinco UTO's mais abundantes, compreendendo uma representação gráfica da abundância relativa para cada dia de amostragem, calculada pela fórmula apresentada por BROWER \& ZAR (1984): $\mathrm{RNj}=\mathrm{Nj} / \Sigma \mathrm{N}$, onde "RNj" é a abundância relativa de uma espécie em um período sucessional "j" (dia de amostragem), "Nj" é a abundância da espécie no período " $\mathrm{j}$ " e " $\Sigma \mathrm{N}$ " é a soma da abundância da espécie em todos os dias de amostragem.

\section{RESULTADOS}

No período de 19 de julho a 29 de agosto de 2001 foram amostrados 17 grupos (UTO's) de macroinvertebrados no substrato artificial e 14 no substrato natural (Tab. I). Porém, os grupos que ocorreram em somente um dos substratos, e que levaram a esta diferença na riqueza, estiveram representados por somente 1 ou 2 indivíduos. Considerando a relação entre a abundância e a área total ocupada em cada tipo de substrato, foram obtidos os valores de 0,6 indivíduos $/ \mathrm{mm}^{2}$ para o substrato artificial e de 0,7 indivíduos $/ \mathrm{mm}^{2}$ para o substrato natural. Os dois substratos também apresentaram semelhanças quanto aos grupos predominantes, destacando-se Diptera (Chironomidae), seguido de Annelida (Oligochaeta), Ephemeroptera (Leptohyphidae) e Trichoptera (Hydroptilidae) (Tab. I).
Tabela I. Abundância ( $\mathrm{N}=$ número total de indivíduos) e Área ocupada $(\mathrm{Ao}=\mathrm{mm} 2)$ dos grupos de macroinvertebrados amostrados em substrato rochoso artificial e natural, ao longo de 42 dias de colonização no Ribeirão da Quinta (valores referentes à soma de todas as coletas).

\begin{tabular}{|c|c|c|c|c|}
\hline \multirow{2}{*}{ Grupos } & \multicolumn{2}{|c|}{ Artificial } & \multicolumn{2}{|c|}{ Natural } \\
\hline & $\mathrm{N}$ & Ao & $\mathrm{N}$ & Ao \\
\hline Mollusca - Ancylidae & 19 & 23,20 & 57 & 75,8 \\
\hline Annelida - Oligochaeta & 195 & 79,00 & 261 & 97,0 \\
\hline Crustacea - Aeglidae & 1 & 6,00 & - & - \\
\hline Acarina & 2 & 0,75 & - & - \\
\hline \multicolumn{5}{|l|}{ Ephemeroptera } \\
\hline Leptohyphidae & 146 & 485,00 & 130 & 505,0 \\
\hline Baetidae & 41 & 149,20 & 29 & 82,1 \\
\hline \multicolumn{5}{|l|}{ Odonata } \\
\hline Corduliidae & - & - & 1 & 6,0 \\
\hline Calopterygidae & 8 & 305,00 & 7 & 135,0 \\
\hline Coenagrionidae & 2 & 25,00 & 7 & 209,5 \\
\hline \multicolumn{5}{|l|}{ Hemiptera } \\
\hline Não identificado & 1 & 0,50 & - & - \\
\hline Hemiptera - Pleidae & - & - & 2 & 3,0 \\
\hline \multicolumn{5}{|l|}{ Trichoptera } \\
\hline Não identificado & 11 & 6,70 & 16 & 19,5 \\
\hline Hydropsychidae & 1 & 0,30 & - & - \\
\hline Hydroptilidae & 98 & 112,40 & 141 & 153,5 \\
\hline Glossosomatidae & 1 & 4,50 & - & - \\
\hline Limnephilidae & 1 & 3,00 & - & - \\
\hline \multicolumn{5}{|l|}{ Coleoptera } \\
\hline Psephenidae & - & - & 1 & 2,3 \\
\hline Elmidae & 13 & 13,80 & 26 & 46,1 \\
\hline \multicolumn{5}{|l|}{ Diptera } \\
\hline Simuliidae & 2 & 9,00 & 1 & 1,2 \\
\hline Chironomidae & 601 & 552,60 & 760 & 736,3 \\
\hline Total & 1143 & 1776,90 & 1439 & 2071,9 \\
\hline
\end{tabular}

Revista Brasileira de Zoologia 21 (2): 287-293, junho 2004 
Para a colonização ao longo do tempo (Tab. II), as dez UTO's presentes no $13^{\circ}$ dia de amostragem corresponderam às dez listadas na tabela I com maiores valores de abundância e/ou área ocupada.

Comparando os substratos artificial e natural nota-se que a riqueza foi semelhante nos dois substratos ao longo do período de 42 dias de colonização (Tab. II), apesar dos valores de abundância e área ocupada terem sido maiores no substrato natural. Porém, os resultados não significativos da análise de variância aplicada para os dados de abundância $(\mathrm{p}=0,205)$ e de área ocupada $(\mathrm{p}=0,488)$ reforçaram a semelhança entre os dois substratos.

Tabela II. Riqueza (número de taxa), abundância ( $N$ = número de indivíduos) e área ocupada $\left(\mathrm{Ao}=\mathrm{mm}^{2}\right)$ de macroinvertebrados encontrados no substrato artificial e natural, retirados em sete dias amostragem, ao longo de 42 dias de colonização no Ribeirão da Quinta (valores referentes à soma de duas réplicas.

\begin{tabular}{crrrrrrrr}
\hline \multirow{2}{*}{$\begin{array}{c}\text { Dia de } \\
\text { amostragem }\end{array}$} & \multicolumn{3}{c}{ Artificial } & & \multicolumn{3}{c}{ Natural } \\
\cline { 2 - 3 } \cline { 7 - 9 } & $\begin{array}{c}\mathrm{n}^{\circ} \\
\text { táxons }\end{array}$ & $\mathrm{N}$ & Ao & & $\begin{array}{c}\mathrm{n}^{\circ} \\
\text { táxons }\end{array}$ & $\mathrm{N}$ & Ao \\
\hline $1^{\circ}$ & 8 & 58 & 73,1 & & 4 & 41 & 41,0 \\
$3^{\circ}$ & 7 & 145 & 235,1 & & 6 & 138 & 101,6 \\
$7^{\circ}$ & 8 & 167 & 251,8 & & 8 & 247 & 267,8 \\
$13^{\circ}$ & 10 & 221 & 256,5 & & 10 & 276 & 404,7 \\
$21^{\circ}$ & 9 & 135 & 262,9 & & 10 & 232 & 305,5 \\
$31^{\circ}$ & 8 & 161 & 262,0 & & 241 & 444,2 \\
$42^{\circ}$ & 11 & 256 & 434,5 & & 11 & 264 & 507,1 \\
\hline Total & 17 & 1143 & 1776,9 & 14 & 1439 & 2071,9 \\
\hline
\end{tabular}

Na análise da abundância ao longo do processo de colonização (Fig. 2), verificou-se um aumento nos dois tipos de substrato, a partir do $1^{\circ}$ dia de amostragem, com uma estabilização a partir do $13^{\circ}$ dia, apesar de um pequeno decréscimo no $21^{\circ}$ dia de amostragem, quando ocorreu uma forte chuva. A análise de variância para medidas repetidas não indicou diferenças significativas entre os dois substratos $(p=0,080)$ para os valores de abundância ao longo do tempo de colonização.

Para os valores de área ocupada, ocorreu uma estabilização no substrato artificial a partir do $3^{\circ}$ dia, com um pico no $42^{\circ}$ dia em decorrência de um aumento brusco na densidade de larvas de Odonata. No substrato natural os valores de área ocupada flutuaram bastante (Fig. 2). Diferenças significativas entre os substratos foram obtidas $(\mathrm{p}=0,019)$ quando analisada a área ocupada ao longo do tempo de colonização.

Analisando o processo de colonização dos quatro grupos predominantes, nota-se que a queda na abundância e área ocupada de Diptera, Annelida e Trichoptera no $21^{\circ}$ dia de amostragem foi acompanhada por um aumento de Ephemeroptera, nos dois substratos (Fig. 3).

Revista Brasileira de Zoologia 21 (2): 287-293, junho 2004

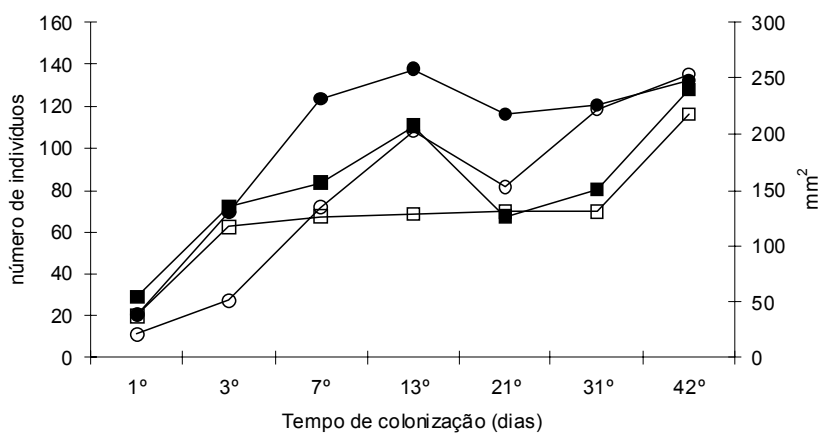

$\begin{array}{ll}\rightarrow-N \text { - Substrato artificial } & -\mathrm{N} \text { - Substrato natural } \\ \square-\text { Ao - Substrato artificial } & - \text { Ao - Substrato natural }\end{array}$

Figura 2. Abundância ( $\mathrm{N}=$ número de indivíduos) e Área ocupada $\left(\right.$ Ao $\left.=\mathrm{mm}^{2}\right)$ de macroinvertebrados amostrados nos substratos artificial e natural (média de duas réplicas), em sete amostras retiradas ao longo de 42 dias de colonização.

Pela análise do processo de sucessão (Fig. 4) verificou-se que nos dois substratos Annelida-Oligochaeta foi um eficiente colonizador inicial, registrando após o $3^{\circ}$ dia sucessivas quedas na abundância. Ephemeroptera-Leptohyphidae foi registrado somente a partir do $7^{\circ}$ dia, mantendo um crescimento contínuo em abundância até o $31^{\circ}$ dia de amostragem. Os demais grupos (Fig. 4) registraram um crescimento contínuo até o $13^{\circ}$ dia, seguido de flutuações na sua abundância até o final da experimentação.

\section{DISCUSSÃO}

A elevada representatividade de insetos no bentos de águas correntes tem sido salientada por vários autores $(e . g$. Hynes 1970, Allan 1995). Dentre os diversos grupos comumente encontrados, Diptera-Chironomidae é o de mais ampla distribuição, sendo freqüentemente o grupo mais abundante em ambientes de água doce (Armitage et al. 1995). No experimento realizado, este grupo foi um dos mais representativos, tanto em abundância quanto em área ocupada, estando presente desde os primeiros dias de amostragem e não apresentando diferença significativa na preferência pelo tipo de substrato colonizado.

O grupo Annelida, representado por Oligochaeta, esteve presente em todo o período de amostragem, sendo o segundo grupo em abundância nos dois substratos. Um dos fatores que possivelmente influenciou sua ocorrência foram as condições do habitat físico, com correnteza relativamente moderada, pouca profundidade e grande quantidade de matéria orgânica depositada sobre o substrato. Analisando a colonização por macroinvertebrados no mesmo local e período, porém utilizando cerâmicas como substrato artificial, constatamos um aumento de sedimento e algas sobre o substrato logo no início 
Substrato natural
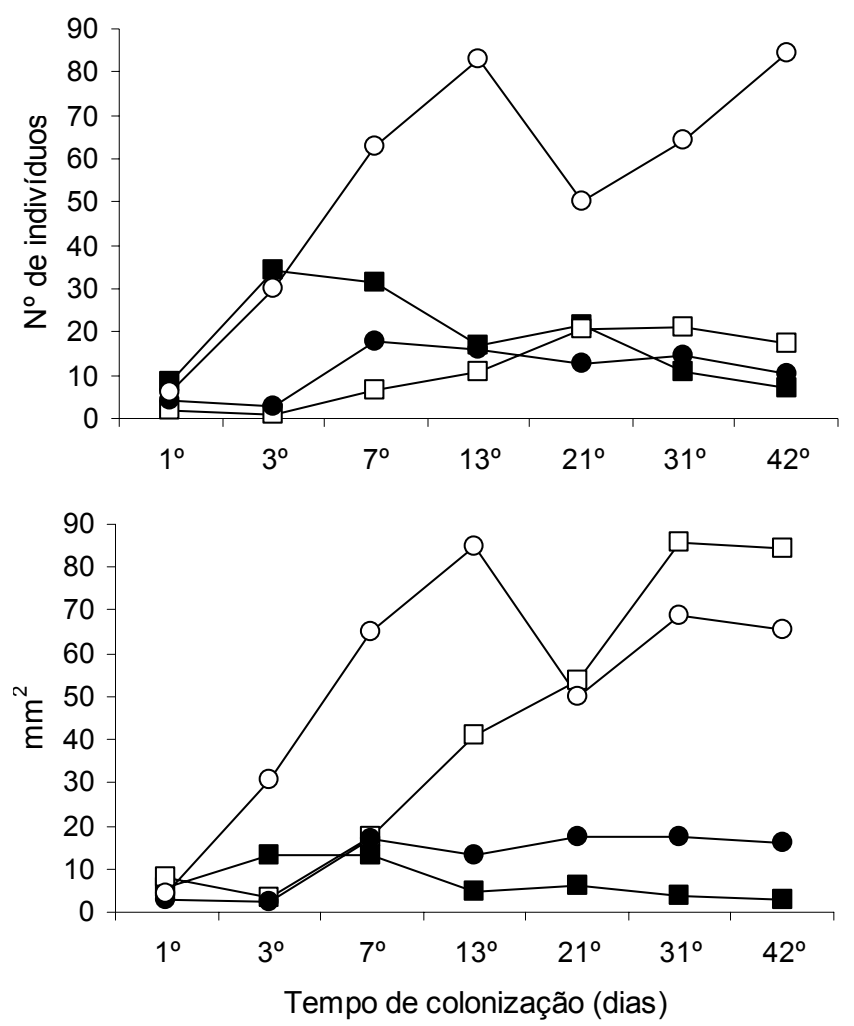

Substrato artificial
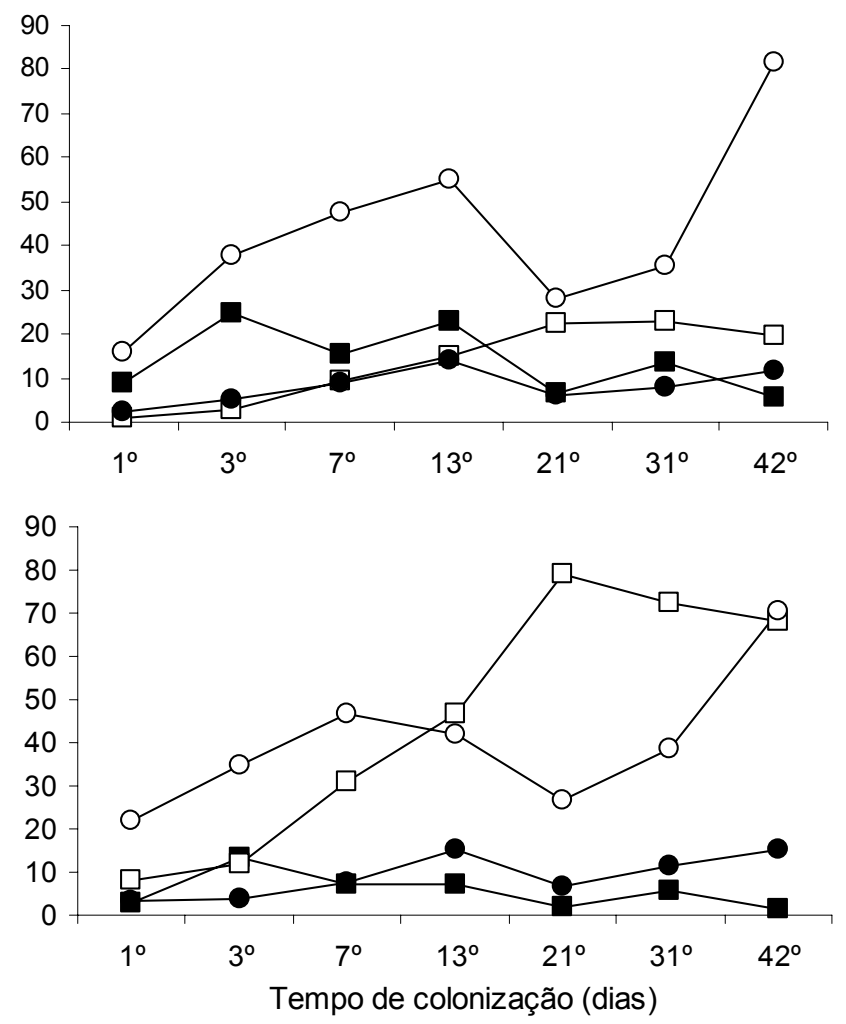

\section{Annelida $-\square-$ Ephemeroptera}

Trichoptera

- Diptera

Figura 3. Abundância ( $\mathrm{N}=$ número de indivíduos) e Área ocupada $\left(\mathrm{Ao}=\mathrm{mm}^{2}\right)$ dos quatro principais táxons amostrados nos substratos natural e artificial (média de duas réplicas), em sete amostras retiradas ao longo de 42 dias de colonização.

do processo de colonização. Estes anelídeos comumente se dispersam por movimentos de rastejamento na camada superficial do substrato (Pennak 1978). Segundo Rincón (1999), a composição do substrato do leito pode ter grande influência na composição de uma comunidade. A realização de furos verticais no substrato artificial provavelmente tornou este substrato mais semelhante ao natural, permitindo o deslocamento vertical dos anelídeos.

No $13^{\circ}$ dia de amostragem notou-se, para os dois substratos, a presença dos principais grupos taxonômicos, demonstrando ser um período ótimo de estabilização na riqueza taxonômica. O tempo mínimo de colonização verificado no experimento, para que ocorresse uma estabilização na abundância e área ocupada de macroinvertebrados, também foi de treze dias. O tipo de substrato artificial utilizado e o tempo para início e estabilização da colonização variam muito entre diferentes trabalhos (veja discussão em MACKAY 1992), dificultando a comparação entre os dados obtidos por diferentes autores e os dados do presente trabalho.
A queda na abundância dos macroinvertebrados no $21^{\circ}$ dia, para os dois tipos de substrato, coincidiu com o único dia durante o experimento em que caiu uma forte chuva, podendo indicar a importância da ação deste fator abiótico na estruturação da comunidade bentônica analisada. Apesar de vários grupos de invertebrados apresentarem adaptações anatômicas e comportamentais para evitar o arraste pela correnteza (Allan 1995), chuvas fortes não previsíveis podem ter um efeito forte. Flecker \& Feifarek (1994) sugerem que distúrbios desta natureza podem exercer um importante papel na estruturação das comunidades de riachos tropicais. O número de insetos pode declinar drasticamente após chuvas de uma magnitude suficiente para alterar a estrutura física do substrato (FleCKer \& Feifarek 1994).

A colonização por Annelida-Oligochaeta desde o primeiro dia de amostragem demonstra ser este grupo um exemplo de um colonizador oportunista. Pela definição de sucessão primária como um processo que se inicia em substrato estéril (BRower \& Zar 1984, Odum 1988), é esperado que nos primei-

Revista Brasileira de Zoologia 21 (2): 287-293, junho 2004 

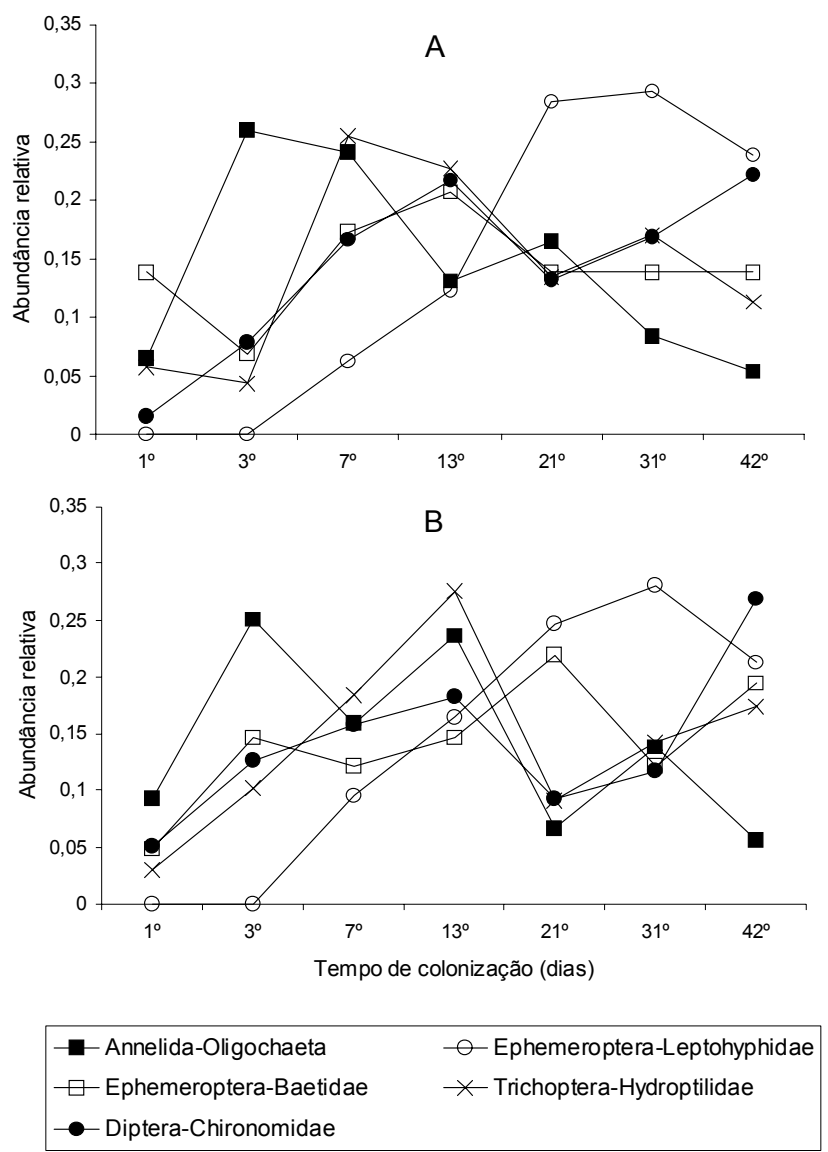

Figura 4. Abundância relativa (soma de duas réplicas) das cinco principais UTO's amostradas nos substratos natural (A) e artificial (B), ao longo dos estágios sucessionais de colonização (42 dias de colonização).

ros estágios sucessionais somente membros de táxons mais oportunistas possam invadir a área em função da pobreza do ambiente.

O aparecimento de Ephemeroptera-Leptohyphidae somente a partir do $7^{\circ}$ dia, para ambos substratos, poderia caracterizá-lo como um colonizador tardio, quando comparado aos outros quatro grupos já instalados desde o início do processo de colonização. Além disso, a ocorrência de flutuações na abundância de Diptera, Annelida e Trichoptera, após a colonização dos substratos por Ephemeroptera-Leptohyphidae, demonstra a importância deste último grupo na estruturação da comunidade estudada. Em um processo de sucessão, conforme o ambiente vai se alterando, com a instalação de produtores e deposição de matéria orgânica, membros de outros táxons adaptados a ambientes já modificados podem colonizar esta nova área, somando-se à comunidade ou excluindo e substituindo seus predecessores (BROWER \& ZAR 1984). Estes gru- pos que tiveram uma flutuação na sua abundância após o aparecimento de Leptohyphidae, classificados como coletoresagregadores e raspadores (MerRitT \& Cummins 1996), poderiam estar em desvantagem na obtenção de matéria orgânica e algas, alimento também utilizado por Ephemeroptera-Leptohyphidae. Assim, em resposta à competição por espaço e/ou alimento ou mesmo à escassez de alimento no local, estes grupos poderiam estar se deslocando para outras áreas. Segundo Townsend \& Hildrew (1975), para algumas espécies o "drift", ou seja, a dispersão da fauna lançando-se na correnteza, pode ser um caminho de redistribuição em resposta à competição por espaço e/ou alimento.

Em experimentos de colonização é importante avaliar a eficiência do substrato utilizado. Uma desvantagem na utilização de estruturas para manipulação é que podem modificar o habitat, tornando difícil distinguir entre os efeitos pretendidos nos tratamentos realizados e os efeitos decorrentes de alterações não intencionais do habitat (Uieda 1999). Segundo MACKAY (1992), apesar da utilização de rochas em bandejas não oferecer as mesmas características que o substrato natural, este substrato é capaz de manter o espaço intersticial e permitir a reprodução dos mesmos efeitos físicos que ocorrem no substrato natural. Doeg et al. (1989), no entanto, salientam que estas estruturas podem obstruir o acesso dos invertebrados por rastejamento, resultando em alguns casos na superestimação do "drift".

No presente trabalho, estes cuidados foram tomados de forma que os substratos utilizados se aproximassem ao máximo do substrato bentônico natural do riacho, mantendo o espaço intersticial (furos verticais) e permitindo o acesso por rastejamento, pois não havia a necessidade de uma base (bandejas) para sustentá-los.

LAMBERTI \& Resh (1985) concluíram que o uso de substrato artificial geralmente resulta numa maior precisão dos dados, quando comparado à amostragem direta em substrato natural. No presente trabalho, o substrato artificial mostrou-se adequado não somente pela facilidade de instalação, mas também por permitir a padronização da área de amostragem dos invertebrados. Sua utilização representou uma eficiente ferramenta na avaliação da biodiversidade de famílias de macroinvertebrados bentônicos presentes no sistema estudado, fornecendo também dados acerca de sucessão ecológica primária.

\section{AGRADECIMENTOS}

A Marcos Callisto e Rosinês Luciana da Motta pelos comentários e sugestões. À CAPES pela bolsa concedida ao primeiro autor durante a realização deste estudo e à FAPESP pelo auxílio financeiro.

\section{REFERÊNCIAS BIBLIOGRÁFICAS}

ALLAN, J.D. 1995. Stream ecology: structure and function of running waters. London, Chapman \& Hall, 388p. 
Armitage, P.D.; P.S. Cranston \& L.C.V. Pinder. 1995. The Chironomidae: The biology and ecology of non-biting midges. London, Chapman \& Hall, 538p.

Brower, J.E. \& J.H. Zar. 1984. Field \& laboratory methods for general ecology. Duduque, W.C. Brown Publishers, 226p.

Doeg, T.J.; R. Marchant; M. Douglas \& P.S. Lake. 1989. Experimental colonization of sand, gravel and stones by macroinvertebrates in the Icheron River, southeastern Australia. Freshwater Biology, Oxford, 22: 57-64.

Flecker, A.S \& B. Feifarek. 1994. Disturbance and the temporal variability of invertebrate assemblages in two Andean streams. Freshwater Biology, Oxford, 31: 131-132.

Freitas, C.E.C. 1998. A colonização de substratos artificiais por macroinvertebrados bênticos em áreas de cachoeira da Amazônia Central. Revista Brasileira de Biologia, Rio de Janeiro, 58 (1): 115-120.

Hauer, F.R. \& V.H. Resh. 1996. Benthic Macroinvertebrates, p. 339-369. In: F.R. HAUER \& G.A. LAMBERTI (Eds). Methods in stream ecology. San Diego, Academic Press, 674p.

Hynes, H.B. 1970. The ecology of running waters. Canada, University of Toronto Press, 555p.

LAmberti, G.A. \& V.H. Resh. 1985. Comparability of introduced tiles and natural substrates for sampling lotic bacteria, algae and macroinvertebrates. Freshwater Biology, Oxford, 15: 21-30.

Lopretto, E.C. \& G. Tell. 1995. Ecosistema de aguas continentales: metodologias para su estudio. Argentina, Ed. Sur,
Tomo III, p. 897-1397.

MACKAY, R.J. 1992. Colonization by lotic macroinvertebrates: a review of processes and patterns. Canadian Journal of Fisheries and Aquatic Science, Otawa, 49: 617-628.

Merritt R.W \& K.W. Cummins. 1996. An introduction to the aquatic insects of North America. Dubuque, Kendal/Hunt, 862p. Odum, E.P. 1988. Ecologia. Rio de Janeiro, Guanabara, 434p.

PENNAK, R.W. 1978. Fresh-water invertebrates of the United States. New York, Wiley-Interscience, 803p.

Resh, V.H. \& D.M. Rosenberg. 1984. The ecology of aquatic insects. New York, Praeger Publishers, 625p.

Rincón, P.A. 1999. Uso do micro-habitat em peixes de riachos: métodos e perspectivas, p. 23-90. In: E.P. CARAMASCHI; R. Mazzoni \& P.R. Peres-Neto (Eds). Ecologia de peixes de riacho. Rio de Janeiro, PPGE-UFRJ, Série Oecologia Brasiliensis, vol. 4, 260p.

Statsoft. 1996. Statistica 5.1 for windows. Tulsa, Computer Program Manual.

SYSTAT. 1997. Systat 7.0 for windows. Chicago, SPSS, 726p.

Townsend, C.R. \& A.G. Hildrew. 1975. Field experiments on the drifting, colonization and continuous redistribution of stream benthos. Journal of Animal Ecology, Oxford, 45: 759-772.

UIEDA, V.S. 1999. Experimentos de manipulação de organismos aquáticos em riachos, p.169-179. In: M.L.M. POMPÊo (Ed.). Perspectivas da Limnologia no Brasil. São Luís, Gráfica e Editora União, 191p.

Recebido em 09.IX.2003; aceito em 28.V.2004. 